\title{
Orphan Drugs of Personalized Medicine in Bulgaria and Their Cost-Effectiveness
}

\author{
$\mathrm{PhD}$ candidate Zhaklin Stoykova-Valcheva \\ Medical University-Varna - Varna, Varna, Bulgaria \\ jacquelinestoykova@gmail.com
}

\begin{abstract}
The orphan drugs development is related to the progress of personalized medicine. The relationship between them is based on a treatment tailored to personalized patient needs. Personalized medicine is defined as "providing the right patient with the right drug, at the right dose and at the right time", while the orphan drug is defined as "intended for the treatment, prevention or diagnosis of a rare disease or condition, which is one that affects less than 200,000 persons in the United States" and no more than 10,000 people for the European Union. The main goal of the article is to study the approved orphan drugs in Bulgaria, determining how many of them are reimbursed by the NHIF and are cost-effective.
\end{abstract}

Keywords: Orphan drug; Personalized medicine; Cost-effectiveness

JEL Code: $A 00$

DOI: https://doi.org/10.36997/IJUSV-ESS/2020.9.3.52

\section{Introduction}

The orphan drugs development is related to the progress of personalized medicine. The relationship between them is based on a treatment tailored to personalized patient needs.

This is the reason that personalized medicine is defined as "providing the right patient with the right medicine, at the right dose and at the right time," (FDA, 2019; Abrahams, 2008; (Stoykova \& Dimitrova-Koeva, 2019) while, today, the orphan medicine is defined as "intended to treat, prevent, or diagnose a rare disease that affects less than 200,000 people for the US and no more than 10,000 people for the EU. (National Organization for Rare Disorders,2020; Committee for Orphan Medicinal Products (COMP), 2000).

\section{Thesis statement and literature review}

The first use of the term "orphan" in the context of drugs was in the 1968 article by Dr. Harry Shirkey, published in The Journal of Pediatrics (Shirkey,1968). In the article, Dr. Harry Shirkey discusses that the study of the efficacy and safety of medicines for children is considered unprofitable by pharmaceutical manufacturers, and often children are also treated as patients with drugs for which there is no information for their side effects. As a result, the lack of research leads to the "orphaning" of certain diseases and makes them "orphans". This is the beginning of "orphan drug" term application and to other therapeutic areas for which no information was available. (Christensen \& Chesney,2003; Sasinowski \& Hull, 2015).

Fifteen years later, in 1983 the first orphan drug legislation is created in the United States with the Orphan Drug Act (ODA). The main goal of stimulating the development of drugs that treat rare diseases." (Nabhan et al., 2018) Today, the law is often considered one of the most successful health legislation enacted in the United States (Novas,2009; Mikami,2019).

The European regulation of orphan medicinal products was introduced by Regulation (EC) № 141/2000 adopted of the European Parliament on 16 December 1999. The legal framework was formally published in the Journal of the European Communities on 22 January 2000 (European Medicines Agency, 2020, Official Journal of the European Communities, 2000). According to, European Union legislation, rare diseases are any disease that affects less than 5 people per 10,000 in the European Union, or 246,000 patients who are part of the European space. The main aim of the article is to study the authorized orphan drugs in Bulgaria, determining how many of them are reimbursed by the NHIF and are cost-effective. (European Commission, 2020, European Medicines Agency, 2020, Enzmann et al., 2012, Stoykova-Valcheva,2020).

\section{Methodology}

The primary research is made and based on - content analysis, compilation and statistical methods for data processing, the secondary research is based on a literature review related to the 
article topic. The article discusses and analyzes data for assessing the economic effectiveness of orphan drugs in Bulgaria.

\section{Results and discussion}

The literature discusses, that the development of orphan drugs is closely associated to the progress of personalized medicine. The connection between rare diseases and personalized medicine is their target in treatment tailored to the individual needs of the patient (Deuchars, 2020, Bulera, 2012).

The results of our study present that orphan drugs for personalized treatment worldwide are - 52 or $33.12 \%$ of the total number of personalized therapies (targeted therapies) with count - 157 or $67 \%$ (Stoykova-Valcheva,2020) (Figure 1).

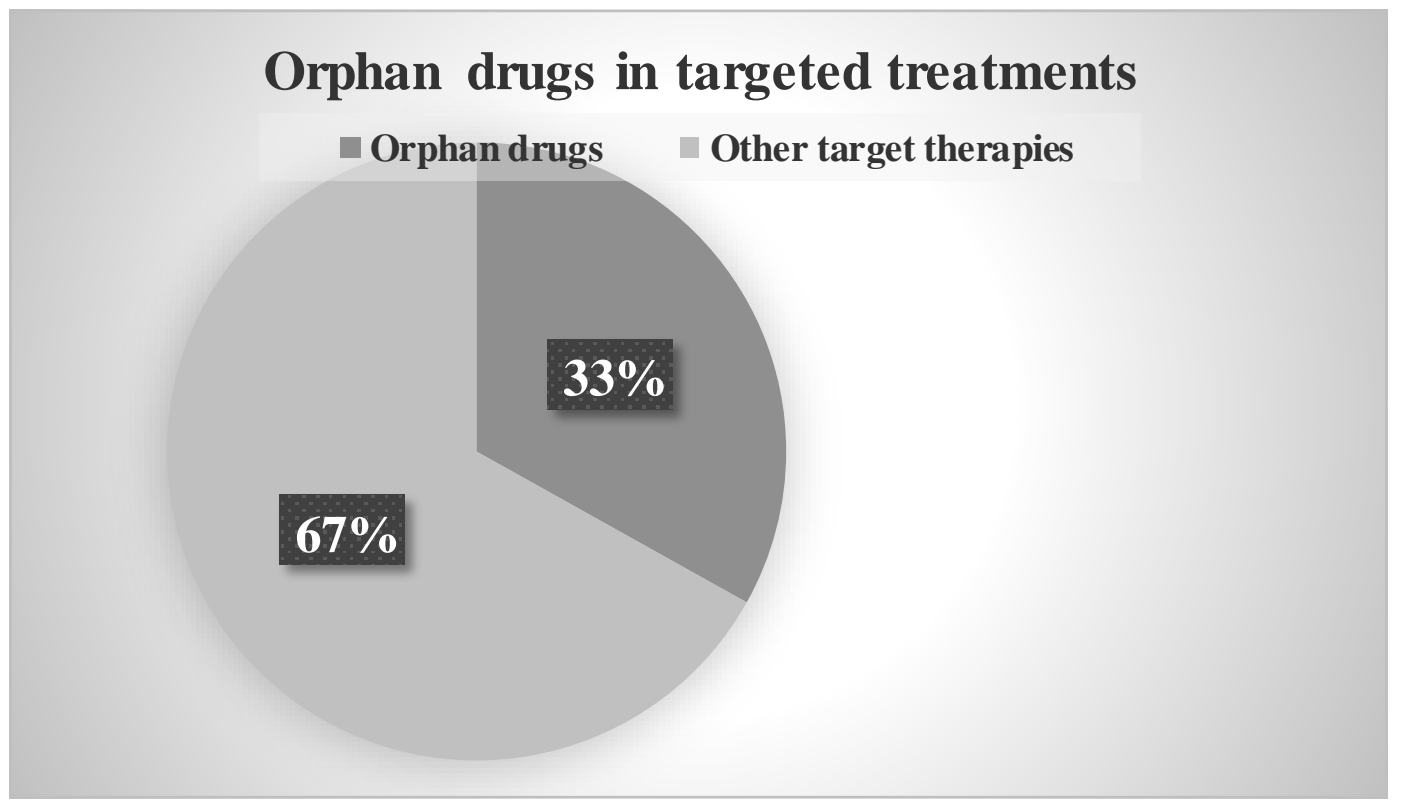

Figure 1. Orphan drugs in targeted treatments

As a result of our research, 52 are all approved orphan drugs worldwide, and 22 or $42.30 \%$ of them are approved for use in Bulgaria. In the last few years (2017-2020) there has been a significant increase in the permitted and reimbursed orphan drugs in Bulgaria. (Figure 2).

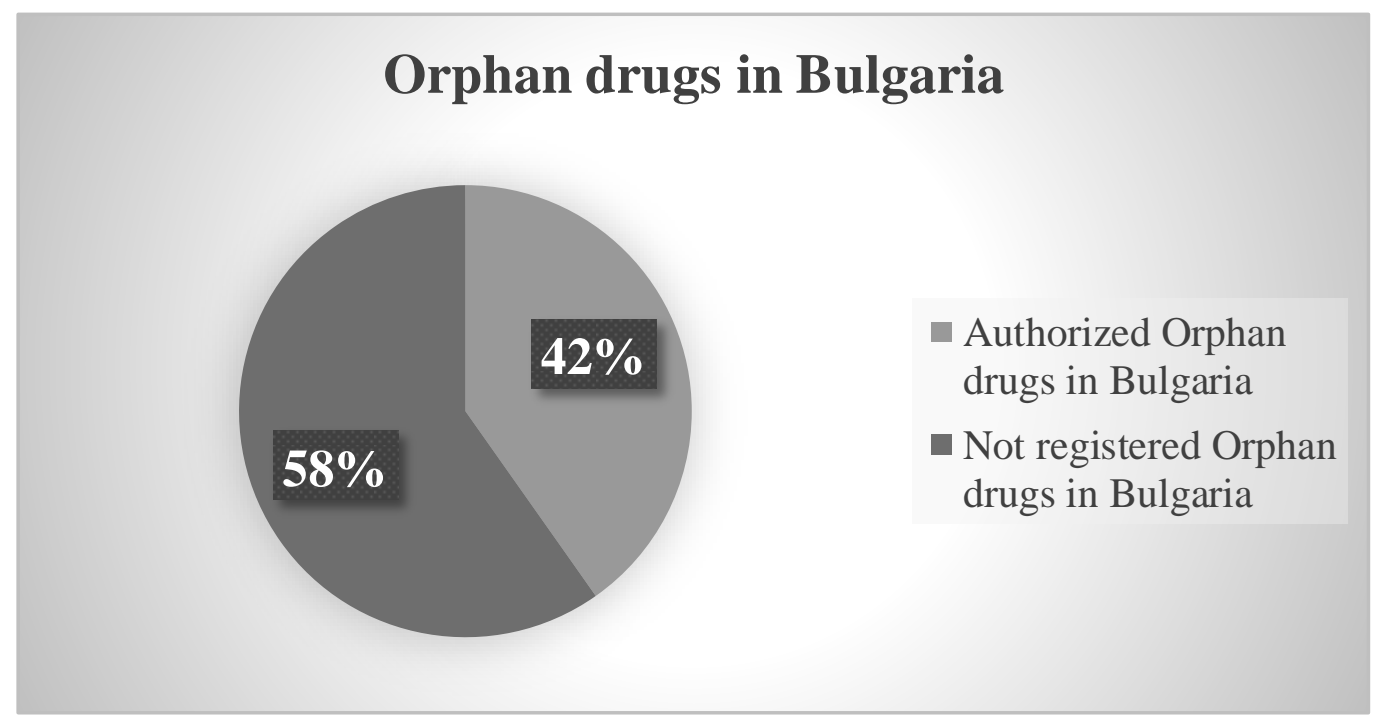

Figure 2. Orphan drugs in Bulgaria 
The results of our study, based on NHIF data, identify 22 orphan drugs authorized for use in Bulgaria. Table 1., presents all therapies, with their The Anatomical Therapeutic Chemical code: (ATC Code) and International Nonproprietary Names (INN), besides, the Table 1., identifies which of these 22 orphan drugs are for target cancer treatment. The primary reason for this is that the most developed therapeutic area in personalized medicine is oncology. Nowadays, targeted therapies are presented in "Personalized Oncology" (Bode \& Dong, 2017; (Stoykova-Valcheva,2020).

The enormous contribution of targeted cancer therapies is the targeted treatment of only cancer cells, as a result healthy cells are with minimal damage. In addition, personalized treatment has minimal side effects than standard methods of treatment (Krzyszczyk et al., 2019, Pierpont et al., 2018; Stoykova-Valcheva,2020).

The result of our research is that $82 \%$ or 18 counts of the orphan drugs in Bulgaria are for cancer treatment and $18 \%$ treat other therapeutic diseases. (Figure 3 ).

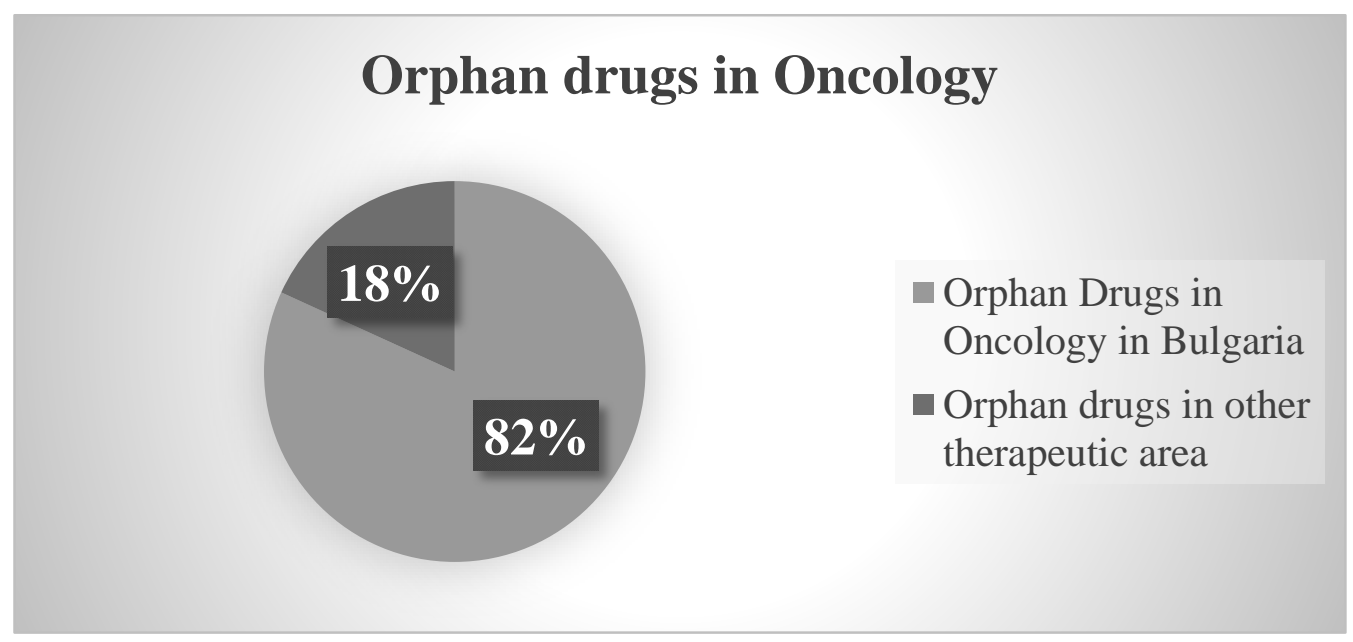

Figure 3. Orphan drugs in Oncology

Results of our research from the Table 1. are that 20 orphan drugs are reimbursed by The National Health Insurance Fund (NHIF) and only 2 drugs are not reimbursed by the NHIF, but are approved for use. (Figure 4).

Table 1. List of orphan drugs in Bulgaria

\begin{tabular}{|c|c|c|c|c|}
\hline № & $\begin{array}{c}\text { Orphan drug - Trade } \\
\text { name }\end{array}$ & INN/ATC & $\begin{array}{c}\text { Orphan drugs in } \\
\text { Oncology }\end{array}$ & $\begin{array}{c}\text { Reimbursed by } \\
\text { the NHIF - } \\
\text { Orphan drugs }\end{array}$ \\
\hline $\mathbf{1}$ & Lynparza & $\begin{array}{c}\text { Olaparib } \\
\text { L01XX46 }\end{array}$ & Oncology & Reimbursed \\
\hline $\mathbf{2}$ & Vimizim & $\begin{array}{c}\text { Elosulfase alfa } \\
\text { A16AB12 }\end{array}$ & $\begin{array}{c}\text { Mucopolysaccharidosis, } \\
\text { type IVA (Morquio A } \\
\text { Syndrome, MPS IVA) }\end{array}$ & Reimbursed \\
\hline $\mathbf{3}$ & Cerdelga & $\begin{array}{c}\text { Eliglustat } \\
\text { A16AX10 }\end{array}$ & $\begin{array}{c}\text { Gaucher disease type 1 } \\
\text { (GD1) }\end{array}$ & Reimbursed \\
\hline $\mathbf{4}$ & Blincyto & $\begin{array}{c}\text { Blinatumomab } \\
\text { L01XC19 }\end{array}$ & Oncology & Reimbursed \\
\hline $\mathbf{5}$ & Alecensa & $\begin{array}{c}\text { Alectinib } \\
\text { L01XE36 }\end{array}$ & Oncology & Reimbursed \\
\hline $\mathbf{6}$ & Bavencio & Avelumab & Oncology & Reimbursed \\
\hline $\mathbf{7}$ & Rydapt & Midostaurin & Oncology & Reimbursed \\
\hline
\end{tabular}


ИЗВЕСТИЯ НА СЬЮЗА НА УЧЕНИТЕ - ВАРНА

\begin{tabular}{|c|c|c|c|c|}
\hline 8 & Imfinzi & $\begin{array}{c}\text { Durvalumab } \\
\text { L01XC28 }\end{array}$ & Oncology & Reimbursed \\
\hline 9 & Kymriah & Tisagenlecleucel & Oncology & Not reimbursed \\
\hline 10 & Palynziq & $\begin{array}{l}\text { Pegvaliase } \\
\text { A16AB19 }\end{array}$ & Phenylketonuria (PKU)) & Not reimbursed \\
\hline 11 & Onpattro & $\begin{array}{c}\text { Patisiran } \\
\text { N07XX12 }\end{array}$ & $\begin{array}{c}\text { Hereditary transthyretin- } \\
\text { mediated amyloidosis } \\
\text { (hATTR } \\
\text { amyloidosis) } \\
\end{array}$ & Reimbursed \\
\hline 12 & Adcetris & $\begin{array}{c}\text { Brentuximab vedotin } \\
\text { L01XC12 }\end{array}$ & Oncology & Reimbursed \\
\hline 13 & Kyprolis & $\begin{array}{l}\text { Carfilzomib } \\
\text { L01XX45 }\end{array}$ & Oncology & Reimbursed \\
\hline 14 & Darzalex & $\begin{array}{l}\text { Daratumumab } \\
\text { L01XC24 }\end{array}$ & Oncology & Reimbursed \\
\hline 15 & Sprycel & $\begin{array}{l}\text { Dasatinib } \\
\text { L01XE06 }\end{array}$ & Oncology & Reimbursed \\
\hline 16 & Xgeva & $\begin{array}{l}\text { Denosumab } \\
\text { M05BX04 }\end{array}$ & Oncology & Reimbursed \\
\hline 17 & Imbruvica & $\begin{array}{c}\text { Ibrutinib } \\
\text { L01XE27 }\end{array}$ & Oncology & Reimbursed \\
\hline 18 & Ninlaro & $\begin{array}{l}\text { Ixazomib } \\
\text { L01XX50 }\end{array}$ & Oncology & Reimbursed \\
\hline 19 & Tasigna & $\begin{array}{l}\text { Nilotinib } \\
\text { L01XE08 }\end{array}$ & Oncology & Reimbursed \\
\hline 20 & Iclusig & $\begin{array}{l}\text { Ponatinib } \\
\text { L01XE24 }\end{array}$ & Oncology & Reimbursed \\
\hline 21 & Cyramza & Ramucirumab & Oncology & Reimbursed \\
\hline 22 & Actemra /RoActemra & $\begin{array}{l}\text { Tocilizumab } \\
\text { L04AC07 }\end{array}$ & Oncology & Reimbursed \\
\hline
\end{tabular}

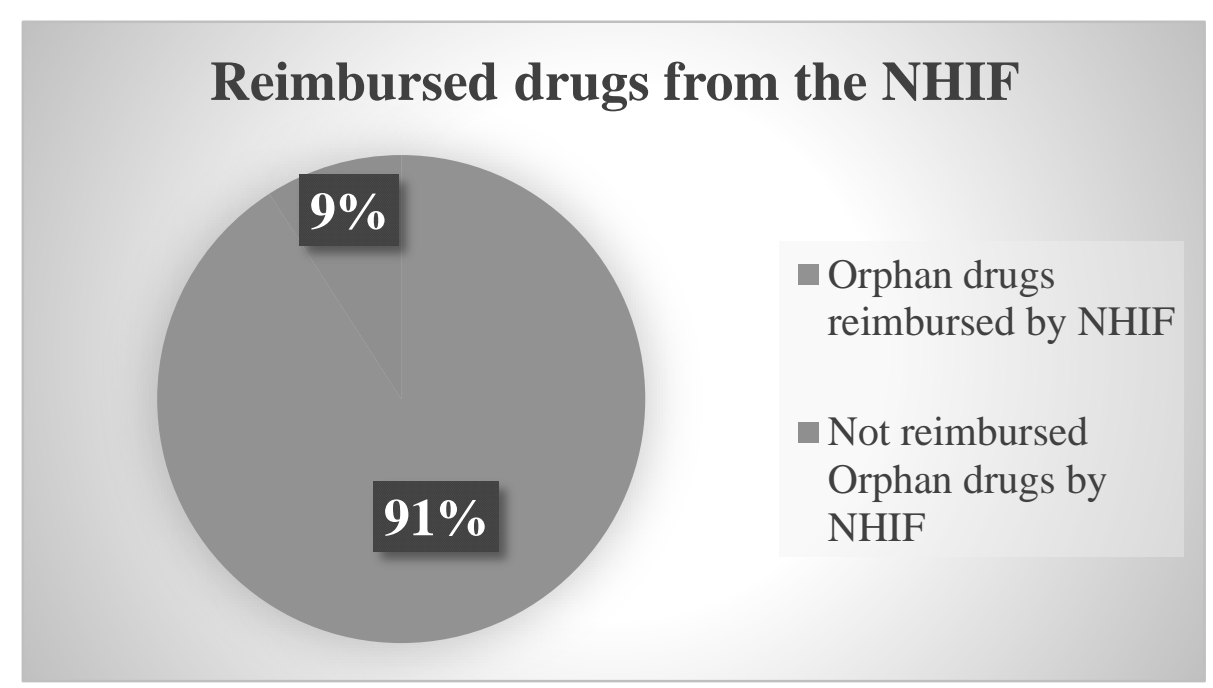

Figure 4. Reimbursed drugs from the NHIF

1. As a result of our own research, we identify that Lynparza is reimbursed targeted therapy by the NHIF and is an orphan drug used to treat ovarian cancer with BRCA mutation and fallopian tube cancer (European Medicines Agency, 2020; National Council On Prices and Reimbursement Of Medicinal Products, 2020). According to the results of the analyzed literature, the therapy is cost-effective treatment compared to platinum-based chemotherapy indicated for first-line treatment (Tan et al.,2019). In agreement with the health insurance fund in Italy, Lynparza as a maintenance 
therapy could be cost-effective over a 50-year time horizon (Armeni et al.,2020; HАУKAOFFNEWS, 2018).

2. Vimizim is an orphan drug to treat a rare disease - Morquio syndrome, also known as Mucopolysaccharidosis Type IV (European Medicines Agency, 2020). The therapy is reimbursed by the NHIF and is cost-effective. According to the studied data, Vimizim proves its therapeutic efficacy and safety in clinical trials. Despite its high price of BGN 1,772.24 for a VAT wholesaler, Vimizim is an indispensable therapy for the treatment of this rare disease with proven health and economic benefits (National Council On Prices and Reimbursement Of Medicinal Products, 2020; Vekov \& Tznakov,2018; Canadian Agency for Drugs and Technologies in Health (CADTH), 2015; Cooper et al.,2015).

3. Cerdelga is orphan drug reimbursed at the highest price by the NHIF and it has the price of a wholesaler with VAT - BGN 38,835.23, (National Council On Prices And Reimbursement Of Medicinal Products, 2020). The therapy is for the treatment of the rare Gaucher disease type 1 (European Medicines Agency, 2020; (Stoykova-Valcheva,2020). The results of our studies identify that the therapy could be cost-effective, but more research is needed to be done on the subject (Balwani et al., 2016; Smid \& Hollak, 2014; National Institute For Health And Care Excellence, 2016).

4. Blincyto is an orphan drug used to treat Acute lymphoblastic leukemia (ALL) for patients over 1 year of age (European Medicines Agency(2020). The National Health Insurance Fund (NHIF) reimburse the therapy and as a result of our studies, Blincyto is a cost-effective therapy compared to standard chemotherapy in the treatment of ALL. The orphan drug improves the life quality of patients (National Council On Prices And Reimbursement Of Medicinal Products,2020; Delea et al.,2017; Delea et al.,2019).

5. Alecensa is an orphan drug used to treat Non-small cell lung cancer (NSCLC), the therapy is reimbursed by the NHIF. According to our studies, Alecensa is a cost-effective therapy compared to Xalkori, the Alecensa increases the chance of lack of disease progression (NSCLC) and improved quality of life (Carlson et al.,2018; Ravasio et al.,2019; Chu, 2017).

6. Bavencio is an orphan drug used as monotherapy in the treatment of adult patients with Merkel cell carcinoma, the therapy is reimbursed by the NHIF (European Medicines Agency, 2020; National Council On Prices And Reimbursement Of Medicinal Products,2020). The results of our studies are that Bavencio is not cost-effective compared to the other used therapy-Sutent (Bullement et al.,2019; Lu et al.,2020)

7. Rydapt is an orphan drug reimbursed by the NHIF. The therapy is cost effective in the treatment of newly diagnosed acute myeloid leukemia (AML) - a positive for FLT3 mutation (National Council On Prices And Reimbursement Of Medicinal Products, 2020; Stein et al.,2019; Tremblay et al., 2018).

8. Imfinzi is an orphan drug to treat locally advanced, inoperable non-small cell lung cancer (NSCLC). Targeted therapy is reimbursed by the NHIF.As a result of our research, Imfinzi is one of many examples where expensive immunotherapies are cost-effective and improve quality of life (European Medicines Agency, 2020; Criss et al.,2019, Armeni et al. 2020).

9. Kymriah is an orphan drug (European Medicines Agency, 2020) and as a result of our research this is the targeted therapy with the highest price that is allowed for use with the price of a wholesaler with VAT - 657170.88 BGN in Bulgaria, (NATIONAL COUNCIL ON PRICES AND REIMBURSEMENT OF MEDICINAL PRODUCTS,2020). The orphan drug is for the treatment of acute lymphoblastic leukemia (ALL) and Diffuse B-cell lymphoma (DLBCL) (European Medicines Agency, 2020; (Stoykova-Valcheva,2020). The results of our examination is that Kymriah is a costeffective targeted therapy that contributes with over 9 years of life (Whittington et al.,2018;Slater,2020).

10. Palynziq is an orphan drug used to treat the rare genetic disease phenylketonuria (PKU). The therapy is approved for use in Bulgaria, but is not reimbursed by NHIF (European Medicines Agency, 2020, National Council On Prices And Reimbursement Of Medicinal Products,2020). The 
results of the studies are that there is still no cost-effectiveness analysis for Palynziq, the treatment with the therapy could be cost - effective, if it increases life expectancy (Zori et al.,2019; Hydery \& Coppenrath , 2019).

11. Onpattro is an orphan drug used to treat $f$ hereditary transthyretin-mediated amyloidosis (hATTR amyloidosis) (European Medicines Agency,2020). Therapy for this rare disease is reimbursed by the NHIF. As a result of our research, Onpattro is a cost-effective therapy due to its high cost compared to the other best maintenance therapy. (Pharmacoeconomic Review Report, 2019; The Institute for Clinical and Economic Review (ICER) ,2018; Mickle et al., 2019).

12. Adcetris is an orphan drug for the treatment of Hodgkin's Lymphoma (European Medicines Agency, 2020). Targeted therapy is reimbursed by the NHIF and as a result of our studies, it is cost-effective, even in stage III / IV of the disease. (National Council On Prices And Reimbursement Of Medicinal Products, 2020; Caffrey,2018; Delea et al.,2019).

13. Kyprolis is an orphan drug used to treat multiple myeloma (European Medicines Agency, 2020). NHIF reimburse the therapy and, according to the studied literature, is costeffective compared to Velcade (Amgen, 2012, Jakubowiak et al., 2016).

14. Darzalex is an orphan drug for the treatment of multiple myeloma (European Medicines Agency, 2020). NHIF reimburse the target therapy, as a result of our research, Darzalex is a costineffective therapy due to its high cost (Zlang et al.,2018; Peligra et al.,2017).

15. Sprycel is an orphan drug for the treatment of chronic myeloid leukemia (CML) and acute lymphoblastic leukemia (ALL) (European Medicines Agency, 2020). NHIF reimburse the target therapy. As a result of our studies, Sprycel is a cost-effective targeted therapy compared to failed treatment with another therapy, Imatinib, due to patients' resistance to treatment (Taylor et al., 2012; Stoykova-Valcheva,2020).

16. Xgeva, an orphan drug (European Medicines Agency, 2020), reimbursed by the NHIF. As a result of our studies, this therapy is cost-effective in the treatment of advanced malignancies affecting the bones and contributes 7 years of life and QALYs 3.67., And leads to a long-term reduction in total costs (Terpos et al., 2019, Rasulova, 2013; Stoykova-Valcheva,2020).

17. Imbruvica is an orphan drug used to treat mantle cell lymphoma (European Medicines Agency, 2020). According to the literature, Imbruvica is a cost-ineffective therapy due to its high cost (Barnes, 2018, Patel et al., 2020).

18. Ninlaro is an orphan drug for the treatment of adult patients with multiple myeloma in combination with lenalidomide and dexamethasone (European Medicines Agency, 2020). NHIF reimburse the therapy and according to the results obtained, treatment with Ninlaro in combination with lenalidomide and dexamethasone is cost-effective compared to other alternative therapies, contributing to a better quality of life (Cai et al.,2019; Alkhatib et al.,2017).

19. Tasigna is an orphan drug (European Medicines Agency, 2020), for the treatment of chronic myeloid leukemia (CML). The therapy is reimbursed by the NHIF and the result of our research is that the orphan drug is a cost-effective, contributing to an additional 15 years saved life without disease progression (Romero et al.2014, Kantarjian et al., 2011; Stoykova-Valcheva,2020).

20. Iclusig is an orphan drug for the treatment of chronic myeloid leukemia (CML) and acute lymphoblastic leukemia, the therapy is reimbursed by the NHIF. As a result of our research, targeted therapy is cost-effective, improving the health and quality of life of patients (Vellopoulou et al, 2017; The National Institute for Health and Care Excellence(NICE), 2017).

21.Cyramza is an orphan drug used to treat several diseases of stomach cancer, colorectal cancer, non-small cell lung cancer and hepatocellular carcinoma (European Medicines Agency, 2020). Targeted therapy is reimbursed by the NHIF. As a result of our research, Cyramza is a costeffective therapy due to its minimal additional benefit and high additional costs for QALY (Saito et al.,2017; Zheng et al.,2020).

22. Actemra / RoActemra is an orphan drug for the treatment of rheumatoid arthritis (RA), the therapy is reimbursed by the NHIF (European Medicines Agency, 2020). As a result of the literature studied, treatment with Actemra / RoActemra is cost-effective for patients with 
rheumatoid arthritis in need of biological monotherapy (Athanasakis et al.,2016;Diamantopoulos et al.,2012).

As a result of the studied cost-effectiveness analyzes of orphan drugs in Bulgaria, 15 orphan drugs are cost-effective, 2- orphan drugs could be cost-effective under certain conditions and 5orphan drugs are cost-ineffective. (Figure 5)

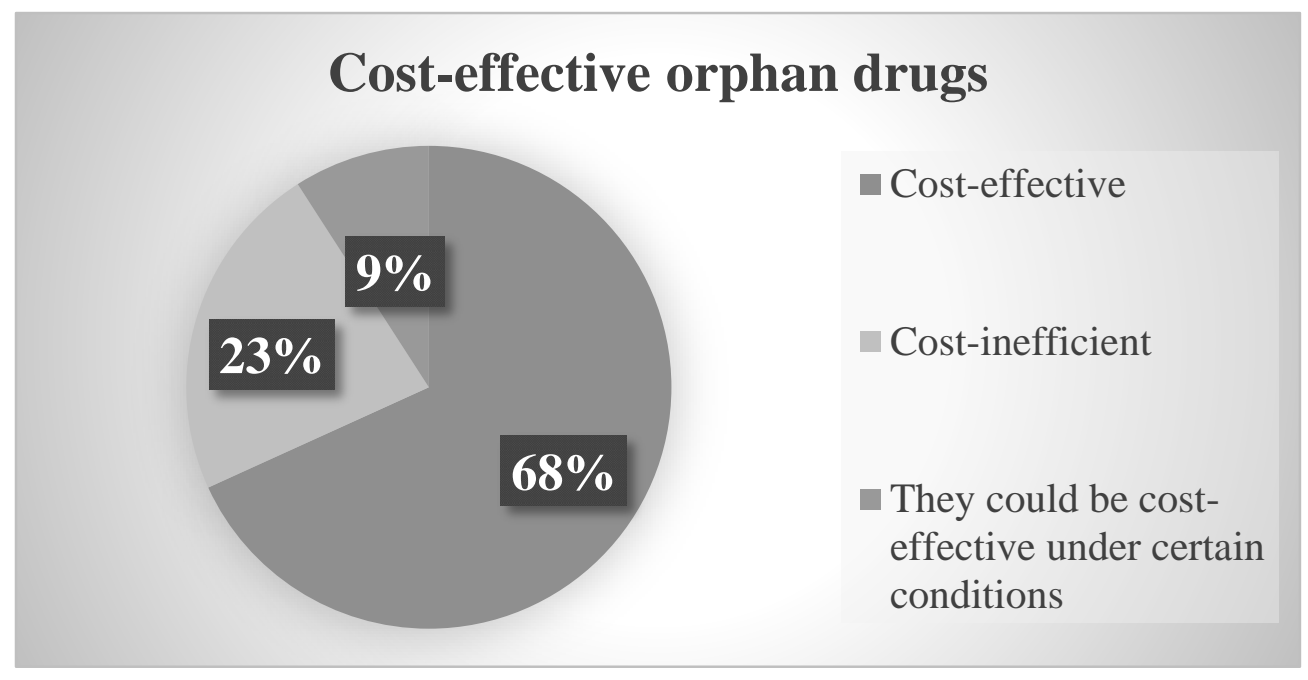

Figure 5. Cost-effective orphan drugs

\section{Conclusion}

In conclusion of our primary research the Bulgarian healthcare system faces the challenge of identifying the cost-effectiveness of expensive orphan drugs. The analysis of our research shows that despite of the high cost of orphan drugs, they are cost -effective with $68 \%$, and they improve patients' quality of life. Many years the term rare disease indicate illness that affects very small percentage of the population, but nowadays in 2020, we could say that the rare disease are not so rare with count 300 million of people in 2020. In this scenario the healthcare systems and the patients have the need of cost-effective treatments - today presented by personalized medicine and orphan drugs.

\section{References}

1. Abrahams,E. (2008) Right Drug—Right Patient—Right Time: Personalized Medicine Coalition. Clinical and Translational Science 1(1):11-2

2. Alkhatib,N., McBride,A., Agarwal,A., Mutairi,A.,Anwer,F., Abraham,I.(2017)Cost effectiveness of carfilzomib $(C A R)$, ixazomib (IXA), elotuzumab (ELO), or daratumumab (DAR) with lenalidomide and dexamethasone $(L E N+D E X)$ vs $L E N+D E X$ in relapsed/refractory multiple myeloma $(R / R M M)$. Journal of Clinical Oncology 35(15_suppl):8030-8030 Follow journal DOI: 10.1200/JCO.2017.35.15_suppl.8030

3. Amgen(2012) Amgen's Statement on Cost Effectiveness of KYPROLIS ${ }^{\circledR}$ (carfilzomib) Compared to Velcade ${ }^{\circledR}$ (bortezomib) in Relapsed or Refractory Multiple Myeloma, Published in Expert Review of Hematology, https://www.amgen.com/media/our-perspective/amgens-statement-on-cost-effectiveness-of-kyprolis-compared-tovelcade/

4. Armeni, P., Borsoi, L., Fornaro, G., Jommi, C., Grossi, F., \& Costa, F. (2020). Cost-effectiveness and Net Monetary Benefit of Durvalumab Consolidation Therapy Versus No Consolidation Therapy After Chemoradiotherapy in Stage III Non-small Cell Lung Cancer in the Italian National Health Service. Clinical therapeutics, 42(5), 830-847. https://doi.org/10.1016/j.clinthera.2020.03.012

5. Armeni,P.,Borsoi,L.,Fornaro,G.,Jommi,C.,Colombo,N.,Costa,F.(2020)Cost-Effectiveness and Net Monetary Benefit of Olaparib Maintenance Therapy Versus No Maintenance Therapy After First-line Platinum-based Chemotherapy in Newly Diagnosed Advanced BRCA1/2-mutated Ovarian Cancer in the Italian National Health Service, Clinical therapeutics, VOLUME 42, ISSUE 7, P1192-1209.E12, https://doi.org/10.1016/j.clinthera.2020.04.015

6. Athanasakis, K., Tarantilis, F., Tsalapati, K., Konstantopoulou, T., Vritzali, E., \& Kyriopoulos, J. (2015). Costutility analysis of tocilizumab monotherapy in first line versus standard of care for the treatment of rheumatoid 
arthritis in Greece. Rheumatology international, 35(9), 1489-1495. https://doi.org/10.1007/s00296-015-3253-x

7. Balwani, M., Burrow, T. A., Charrow, J., Goker-Alpan, O., Kaplan, P., Kishnani, P. S., Mistry, P., Ruskin, J., \& Weinreb, N. (2016). Recommendations for the use of eliglustat in the treatment of adults with Gaucher disease type 1 in the United States. Molecular genetics and metabolism, 117(2), 95-103. https://doi.org/10.1016/j.ymgme.2015.09.002

8. Barnes, J. I., Divi, V., Begaye, A., Wong, R., Coutre, S., Owens, D. K., \& Goldhaber-Fiebert, J. D. (2018). Costeffectiveness of ibrutinib as first-line therapy for chronic lymphocytic leukemia in older adults without deletion 17p. Blood advances, 2(15), 1946-1956. https://doi.org/10.1182/bloodadvances.2017015461

9. Bode, A. M., \& Dong, Z. (2017). Precision oncology- the future of personalized cancer medicine?. NPJ precision oncology, 1(1), 2.https://doi.org/10.1038/s41698-017-0010-5

10. Bulera,S.(2012) Orphan Drugs Or Personalized Medicine? https://eureka.criver.com/orphan-drugs-orpersonalized-medicine/

11. Bullement, A., Nathan, P., Willis, A., Amin, A., Lilley, C., Stapelkamp, C., Hatswell, A., Pescott, C., Bharmal, M. (2019). Cost Effectiveness of Avelumab for Metastatic Merkel Cell Carcinoma. PharmacoEconomics - open, 3(3), 377-390. https://doi.org/10.1007/s41669-018-0115-y

12. Caffrey, M. (2018) Authors Find Brentuximab Vedotin Cost-Effective for Treatment of Advanced Hodgkin Lymphoma https://www.ajmc.com/view/authors-find-brentuximab-vedotin-costeffective-for-treatment-ofadvanced-hodgkin-lymphoma

13. Cai, H., Zhang, L., Li, N., Zheng, B., \& Liu, M. (2019). Cost-effectiveness analysis on binary/triple therapy on the basis of ixazomib or bortezomib for refractory or relapsed multiple myeloma. Leukemia \& lymphoma, 60(12), 2951-2959. https://doi.org/10.1080/10428194.2019.1620947

14. Canadian Agency for Drugs and Technologies in Health (CADTH).(2015) Common Drug Review elosulfase alfa (Vimizim) $\quad(2 \quad \mathrm{mg} / \mathrm{kg} \quad$ of body weight), https://www.cadth.ca/sites/default/files/cdr/pharmacoeconomic/SR0389_Vimizim_PE_Report_e.pdf

15. Carlson, J., Suh, K., Orfanos, P., Wong, W. (2018). Cost Effectiveness of Alectinib vs. Crizotinib in First-Line Anaplastic Lymphoma Kinase-Positive Advanced Non-Small-Cell Lung Cancer. PharmacoEconomics, 36(4), 495504. https://doi.org/10.1007/s40273-018-0625-6

16. Christensen, M. Chesney, R. (2003) Has the 'therapeutic orphan' finally been adopted? J Pediatr Pharmacol Ther. 8(3):175-6. doi: 10.5863/1551-6776-8.3.175. PMID: 23118676; PMCID: PMC3469141.

17. Chu,M. (2017) Roche Korea's lung cancer drug increases cost-effectiveness,Korea Biomedical Review(KBR); www.koreabiomed.com/news/articleView.html?idxno=1579

18. Committee for Orphan Medicinal Products (COMP) (2000) Regulation (EC) No 141/2000, https://www.ema.europa.eu/en/committees/committee-orphan-medicinal-products-comp

19. Cooper, K., Kalita, N., Harris, P., Cook, A., Shepherd, J., Payne, L. and Loveman, E. (2015) Clinical-effectiveness and cost-effectiveness of elosulfase alfa for treating mucopolysaccharidosis type IVA (Morquio A syndrome) (Health Technology Assessment, 14/63/01) NIHR Journals Library

20. Criss, S., Mooradian, M., Sheehan, D., Zubiri, L., Lumish, M., Gainor, J., Reynolds, K., \& Kong, C. (2019). Costeffectiveness and Budgetary Consequence Analysis of Durvalumab Consolidation Therapy vs No Consolidation Therapy After Chemoradiotherapy in Stage III Non-Small Cell Lung Cancer in the Context of the US Health Care System. JAMA oncology, 5(3), 358-365. https://doi.org/10.1001/jamaoncol.2018.5449

21. Delea, T. Sharma, A., Grossman, A., Eichten, C., Fenton, K., Josephson, N., Richhariya, A., \& Moskowitz, A. (2019). Cost-effectiveness of brentuximab vedotin plus chemotherapy as frontline treatment of stage III or IV classical Hodgkin lymphoma. Journal of medical economics, 22(2), 117-130. https://doi.org/10.1080/13696998.2018.1542599

22. Delea, T., Amdahl, J., Boyko, D., Hagiwara, M., Zimmerman, Z., Franklin, J., Cong, Z., Hechmati, G.,Stein, A. (2017). Cost-effectiveness of blinatumomab versus salvage chemotherapy in relapsed or refractory Philadelphiachromosome-negative B-precursor acute lymphoblastic leukemia from a US payer perspective. Journal of medical economics, 20(9), 911-922. https://doi.org/10.1080/13696998.2017.1344127

23. Delea, T., Zhang, X., Amdahl, J., Boyko, D., Dirnberger, F., Campioni, M., Cong, Z. (2019). Cost Effectiveness of Blinatumomab Versus Inotuzumab Ozogamicin in Adult Patients with Relapsed or Refractory B-Cell Precursor Acute Lymphoblastic Leukemia in the United States. PharmacoEconomics, 37(9), 1177-1193. https://doi.org/10.1007/s40273-019-00812-6

24. Deuchars,K. (2020)Personalized Medicine Is Key to Diagnosing Rare Disease,https://www.healthinsight.ca/advocacy/personalized-medicine-is-key-to-diagnosing-rare-disease/

25. Diamantopoulos, A., Benucci, M., Capri, S., Berger, W., Wintfeld, N., Giuliani, G., \& Ricciardi, W. (2012). Economic evaluation of tocilizumab combination in the treatment of moderate-to-severe rheumatoid arthritis in Italy. Journal of medical economics, 15(3), 576-585. https://doi.org/10.3111/13696998.2012.665110

26. DOI:https://doi.org/10.1093/annonc/mdz426.007

27. Enzmann ,H., Kaestner,B.,Todorova,L., Kamusheva,M.,Vlaskovska ,M.,Petrova,G.(2012) Current Issues in Orphan Drug Regulation in the EU.Arbilis Science Pharmacology 2/2012, https://publishing.arbilis.com/wp- 
content/uploads/2013/09/NF_2012_2_3.pdf

28. European Commission(2020)

Rare

diseases, https://ec.europa.eu/health/non_communicable_diseases/rare_diseases_en

29. European Medicines Agency .(2020) . Onpattro Summary Of Product Characteristics, https://www.ema.europa.eu/en/documents/product-information/onpattro-epar-product-information_en.pdf

30. European Medicines Agency. (2020) Imfinzi $50 \mathrm{mg} / \mathrm{mL}$ concentrate for solution for infusion, Summary of product characteristics information_en.pdf

31. European Medicines Agency.(2020) Vimizim $1 \mathrm{mg} / \mathrm{ml}$ concentrate for solution for infusion, Summary Of Product Characteristics, information_en.pdf

32. European Medicines Agency(2020) Blincyto (blinatumomab), EMA/882824/2018, EMEA/H/C/003731, https://www.ema.europa.eu/en/documents/overview/blincyto-epar-medicine-overview_bg.pdf

$\begin{array}{lllll}33 & \text { European Medicines Agency(2020) Cerdelga (eliglustat) , EMA/393107/2018 }\end{array}$ ,EMEA/H/C/003724,https://www.ema.europa.eu/en/medicines/human/EPAR/cerdelga

34. European Medicines Agency(2020) Kymriah (tisagenlecleucel) EMA/462626/2018, EMEA/H/C/004090, https://www.ema.europa.eu/en/documents/overview/kymriah-epar-medicine-overview_bg.pdf

35. European Medicines Agency(2020) Orphan designation: Overview, https://www.ema.europa.eu/en/humanregulatory/overview/orphan-designation-overview

36. European Medicines Agency(2020)Palynziq, Summary Of Product Characteristics, https://www.ema.europa.eu/en/documents/product-information/palynziq-epar-product-information_en.pdf

37. European Medicines Agency. (2020). Adcetris Summary Of Product Characteristics, https://www.ema.europa.eu/en/documents/product-information/adcetris-epar-product-information en.pdf

38. European Medicines Agency. (2020). Cyramza, Summary Of Product Characteristics, https://www.ema.europa.eu/en/documents/product-information/cyramza-epar-product-information_en.pdf

39. European Medicines Agency. (2020). Darzalex, Summary Of Product Characteristics, https://www.ema.europa.eu/en/documents/product-information/darzalex-epar-product-information_en.pdf

40. European Medicines Agency. (2020). Iclusig, Summary Of Product Characteristics, https://www.ema.europa.eu/en/documents/referral/iclusig-article-20-procedure-product-information_en.pdf

41. European Medicines Agency. (2020). Imbruvica, Summary Of Product Characteristics, https://www.ema.europa.eu/en/documents/product-information/imbruvica-epar-product-information_en.pdf

42. European Medicines Agency. (2020). Kyprolis, Summary Of Product Characteristics, https://www.ema.europa.eu/en/documents/product-information/kyprolis-epar-product-information en.pdf

43. European Medicines Agency. (2020). Ninlaro, Summary Of Product Characteristics, https://www.ema.europa.eu/en/documents/product-information/ninlaro-epar-product-information_en.pdf

44. European Medicines Agency. (2020). RoActemra,Summary Of Product Characteristics,

45. European Medicines Agency. (2020). Sprycel, Summary Of Product Characteristics, https://www.ema.europa.eu/en/documents/product-information/sprycel-epar-product-information_en.pdf

46. European Medicines Agency. (2020). Tasigna, Summary Of Product Characteristics https://www.ema.europa.eu/en/documents/product-information/tasigna-epar-product-information_en.pdf

47. European Medicines Agency. (2020). Xgeva, Summary Of Product Characteristics,

48. European Medicines Agency.(2020) Bavencio $20 \mathrm{mg} / \mathrm{mL}$ concentrate for solution for infusion, Summary Of Product Characteristics, https://www.ema.europa.eu/en/documents/product-information/bavencio-epar-productinformation en.pdf

49. growing role of precision and personalized medicine for cancer treatment. Technology (Singap World Sci). 2018 Sep-Dec; 6(3-4): 79-100. Published online 2019 Jan 11. doi: 10.1142/S2339547818300020, pp. 93-123. doi: 10.1007/978-3-030-01896-2_5.

50. Hydery, T., \& Coppenrath, V. (2019). A Comprehensive Review of Pegvaliase, an Enzyme Substitution Therapy for the Treatment of Phenylketonuria. Drug target insights, 13, 1177392819857089. https://doi.org/10.1177/1177392819857089

51. Jakubowiak, A. J., Campioni, M., Benedict, Á., Houisse, I., Tichy, E., Giannopoulou, A., Aggarwal, S. K., Barber, B. L., \& Panjabi, S. (2016). Cost-effectiveness of adding carfilzomib to lenalidomide and dexamethasone in relapsed multiple myeloma from a US perspective. Journal of medical economics, 19(11), 1061-1074. https://doi.org/10.1080/13696998.2016.1194278

52. Kantarjian, H. M., Giles, F. J., Bhalla, K. N., Pinilla-Ibarz, J., Larson, R. A., Gattermann, N., Ottmann, O. G., Hochhaus, A., Radich, J. P., Saglio, G., Hughes, T. P., Martinelli, G., Kim, D. W., Shou, Y., Gallagher, N. J., Blakesley, R., Baccarani, M., Cortes, J., \& le Coutre, P. D. (2011). Nilotinib is effective in patients with chronic myeloid leukemia in chronic phase after imatinib resistance or intolerance: 24-month follow-up results. Blood, 117(4), 1141-1145. https://doi.org/10.1182/blood-2010-03-277152

53. Krzyszczyk,P., Acevedo,A., Davidoff, E., Timmins,L., Marrero-Berrios,I., Patel,M., White,C., Lowe,Ch., 
Sherba,J., Hartmanshenn,C., O’Neill,K., Balter,M., Fritz, Z., Androulakis,I., and M. L. Y. (2019) The

54. Lu, P., Liang, W., Li, J., Hong, Y., Chen, Z., Liu, T., Dong, P., Huang, H., Zhang, T., \& Jiang, J. (2020). A CostEffectiveness Analysis: First-Line Avelumab Plus Axitinib Versus Sunitinib for Advanced Renal-Cell Carcinoma. Frontiers in pharmacology, 11, 619. https://doi.org/10.3389/fphar.2020.00619

55. Mickle, K., Lasser, K., Hoch, J., Cipriano, L. , Dreitlein, W., \& Pearson, S. (2019). The Effectiveness and Value of Patisiran and Inotersen for Hereditary Transthyretin Amyloidosis. Journal of managed care \& specialty pharmacy, 25(1), 10-15. https://doi.org/10.18553/jmcp.2019.25.1.010

56. Mikami,K. (2019) Orphans in the Market: The History of Orphan Drug Policy, Social History of Medicine, Volume 32, Issue 3, Pages 609-630, https://doi.org/10.1093/shm/hkx098

57. National Council On Prices And Reimbursement Of Medicinal Products. (2020) Vimizim, https://portal.ncpr.bg/registers/pages/register/list-medicament.xhtml

58. National Council On Prices And Reimbursement Of Medicinal Products. (2020). Cerdelga , https://portal.ncpr.bg/registers/pages/register/list-medicament.xhtml

59. National Council On Prices And Reimbursement Of Medicinal Products. (2020). Blincyto, https://portal.ncpr.bg/registers/pages/register/list-medicament.xhtml

60. National Council On Prices And Reimbursement Of Medicinal Products. (2020). Bavencio,https://portal.ncpr.bg/registers/pages/register/list-medicament.xhtml

61. National Council On Prices And Reimbursement Of Medicinal Products. (2020). Rydapt https://portal.ncpr.bg/registers/pages/register/list-medicament.xhtml

62. National Council On Prices And Reimbursement Of Medicinal Products. (2020) Palynziq, https://portal.ncpr.bg/registers/pages/register/list-medicament.xhtml

63. National Council On Prices And Reimbursement Of Medicinal Products. (2020). Adcetris.https://portal.ncpr.bg/registers/pages/register/list-medicament.xhtml

64. National Council On Prices And Reimbursement Of Medicinal Products. (2020) Kymriah, https://portal.ncpr.bg/registers/pages/register/list-medicament.xhtml

65. National Council On Prices And Reimbursement Of Medicinal Products. (2020) Lynparza; https://portal.ncpr.bg/registers/pages/register/list-medicament.xhtml

66. National Institute For Health And Care Excellence .(2016). Highly Specialised Technology Evaluation Eliglustat For Treating Type 1 Gaucher Disease, https://www.nice.org.uk/guidance/hst5/documents/evaluation-consultationdocument-2

67. National Organization for Rare Disorders(2020) What is a rare disease? https://rarediseases.org/rare-diseaseday/about-the-day/

68. Novas,C.(2009) 'Orphan Drugs, Patient Activism and Contemporary Healthcare', Quaderni, 68, 13-23, 18.

69. Official Journal of the European Communities (2000) Regulation (Ec) No 141/2000 Of The European Parliament And Of The Council Of 16 December 1999 on orphan medicinal products,https://eur-lex.europa.eu/legalcontent/EN/TXT/PDF/?uri=CELEX:32000R0141\&from=EN

70. Patel, K., Isufi, I., Kothari, S., Davidoff, A. J., Gross, C. P., \& Huntington, S. F. (2020). Cost-Effectiveness of FirstLine Ibrutinib versus Third-Line in Patients with Untreated Chronic Lymphocytic Leukemia. Blood, blood.2020004922. Advance online publication. https://doi.org/10.1182/blood.2020004922

71. Pelligra, C., Parikh, K., Guo, S., Chandler, C., Mouro, J., Abouzaid, S., \& Ailawadhi, S. (2017). Cost-effectiveness of Pomalidomide, Carfilzomib, and Daratumumab for the Treatment of Patients with Heavily Pretreated Relapsedrefractory Multiple Myeloma in the United States. Clinical therapeutics, 39(10), 1986-2005.e5. https://doi.org/10.1016/j.clinthera.2017.08.010

72. Pharmacoeconomic Review Report: (2019). Patisiran (Onpattro): (Alnylam Netherlands B.V.). Canadian Agency for Drugs and Technologies in Health.

73. Pierpont, T. M., Limper, C. B., \& Richards, K. L. (2018). Past, Present, and Future of Rituximab-The World's First Oncology Monoclonal Antibody Therapy. Frontiers in oncology, 8, 163. https://doi.org/10.3389/fonc.2018.00163

74. Rasulova, N., Lyubshin, V., Arybzhanov, D., Krylov, V., \& Khodjibekov, M. (2013). Effectiveness of bone metastases treatment by sm-153 oxabifore in combination with monoclonal antibody denosumab (xgeva): first experience. World journal of nuclear medicine, 12(1), 19-23. https://doi.org/10.4103/1450-1147.113942

75. Ravasio, R., Tiseo,M., Pradelli, L., Bellone, M., Gervasi, A., Coffani, M.(2019) Cost-effectiveness analysis of alectinib versus crizotinib in first-line treatment of anaplastic lymphoma kinase-positive advanced non-small cell lung cancer, SAGE Publishing; https://doi.org/10.1177/2284240319855072

76. Romero, M., Chávez, D., De Los Ríos, M., \& Alvis-Guzmán, N. (2014). Cost-effectiveness of nilotinib, dasatinib and imatinib as first-line treatment for chronic myeloid leukemia in Colombia, 2012. Biomedica : revista del Instituto Nacional de Salud, 34(1), 48-59. https://doi.org/10.1590/S0120-41572014000100008

77. Saito, S., Muneoka, Y., Ishikawa, T., \& Akazawa, K. (2017). Cost-effectiveness of Paclitaxel + Ramucirumab Combination Therapy for Advanced Gastric Cancer Progressing After First-line Chemotherapy in Japan. Clinical therapeutics, 39(12), 2380-2388. https://doi.org/10.1016/j.clinthera.2017.10.017

78. Sasinowski,F. Hull,A.(2015) A brief history of the name 'orphan drugs' MedCity News; 


\section{IZVESTIA JOURNAL OF THE UNION OF SCIENTISTS - VARNA}

https://medcitynews.com/2015/02/brief-history-name-orphan-drugs/

79. SCIENCEOFFNEWS (2018) The first gene-related breast cancer drug has been approved.https://nauka.offnews.bg/news/Novini_1/Odobriha-parvoto-lekarstvo-za-rak-na-gardata-svarzan-sgenite $101213 . \mathrm{html}$

80. Shirkey,H. (1968) Therapeutic orphans. J Pediatr. Jan;72(1):119-20. doi: 10.1016/s0022-3476(68)80414-7. PMID: 5634934.

81. Slater,H. (2020) Cost-Effectiveness of Tisagenlecleucel in Pediatric Patients with ALL , https://www.cancernetwork.com/view/cost-effectiveness-tisagenlecleucel-pediatric-patients-all

82. Smid,B., Hollak,C.(2014) A systematic review on effectiveness and safety of eliglustat for type 1 Gaucher disease. Expert Opinion on Orphan Drugs; 2(5): 523-529.

83. Stein, E., Xie, J., Duchesneau, E., Bhattacharyya, S., Vudumula, U., Ndife, B., Bonifacio, G., Guerin, A., Li, N., \& Joseph, G. (2019). Cost Effectiveness of Midostaurin in the Treatment of Newly Diagnosed FLT3-Mutated Acute Myeloid Leukemia in the United States. PharmacoEconomics, 37(2), 239-253. https://doi.org/10.1007/s40273-018$0732-4$

84. Stoykova,Zh.,Dimitrova-Koeva,L.(2019) History and development of personalized medicine. Health Economics and Management

85. Stoykova-Valcheva.Zh. (2020) Bulgaria in the age of personalized medicine - challenges and opportunities. Health policy and management ISSN 1313-4981

86. Tan,D., Chan,J., Loke,J.,Hettle,R.,Ghosh,W.,Viswambaram,A.,Yu,C.(2019) Cost-effectiveness of olaparib vs routine surveillance in the maintenance setting for patients with BRCA-mutated advanced ovarian cancer after response to first-line platinum-based chemotherapy in Singapore. Annals of Oncology, VOLUME 30, SUPPLEMENT 9 ,

87. Taylor,M.Mealing,S.,Scott,D.,Clark,J.McKenna,M.,Lebmeier,M.Davis,C.(2012)PSY37 A UK Based CostEffectiveness Analysis of Dasatinib (Sprycel) 100mg Daily Compared to Imatinib (Glivec) 600/800mg Daily as Therapy for Imatinib Failing Chronic Myeloid Leukemia (CML) DOI:https://doi.org/10.1016/j.jval.2012.03.571

88. Terpos, E., Jamotte, A., Christodoulopoulou, A., Campioni, M., Bhowmik, D., Kennedy, L., \& Willenbacher, W. (2019). A cost-effectiveness analysis of denosumab for the prevention of skeletal-related events in patients with multiple myeloma in four European countries: Austria, Belgium, Greece, and Italy. Journal of medical economics, 22(8), 766-776. https://doi.org/10.1080/13696998.2019.1606002

89. The Institute for Clinical and Economic Review (ICER). (2018) Inotersen and Patisiran for Hereditary Transthyretin Amyloidosis: Effectiveness and Value. https://icer-review.org/wpcontent/uploads/2018/02/ICER Amyloidosis_Evidence_Report 082918-1.pdf

90. The National Institute for Health and Care Excellence(NICE). (2017)Ponatinib for treating chronic myeloid leukaemia and acute lymphoblastic leukaemia, https://www.nice.org.uk/guidance/ta451

91. Tremblay, G., Dolph, M., Patel, S., Brandt, P., \& Forsythe, A. (2018). Cost-effectiveness analysis for midostaurin versus standard of care in acute myeloid leukemia in the United Kingdom. Cost effectiveness and resource allocation : C/E, 16, 33. https://doi.org/10.1186/s12962-018-0153-4

92. U.S. Food and Drug Administration (FDA)(2019) PRECISION MEDICINE: UNDERSTANDING. https://www.fda.gov/media/138005/download

93. Vekov.T, Tznakov,S. (2018) Cost-effectiveness analysis of therapeutic alternatives for treatment of mucopolysaccharidosis type IVa in Bulgaria- 10, № 2, 3-8. Faculty of Pharmacy, Medical University - Pleven

94. Vellopoulou,K.,Kourlaba,G.,Giannoulia,P.Panagiotidis,P.Maniadakis,N.(2017) Cost-Effectiveness of Ponatinib in The Treatment of Patients with Acute Lymphoblastic Leukemia with Philadelphia Chromosome Positive (PH+ ALL), Suitable for Allogeneic Stem Cell Transplant, in Greece Value in HealthVol. 21 DOI:https://doi.org/10.1016/j.jval.2017.08.232

95. Whittington, M., McQueen, R., Ollendorf, D. , Kumar, V., Chapman, R., Tice, J., Pearson, S. \& Campbell, J. (2018). Long-term Survival and Value of Chimeric Antigen Receptor T-Cell Therapy for Pediatric Patients With Relapsed or Refractory Leukemia. JAMA pediatrics, 172(12), 1161-1168. https://doi.org/10.1001/jamapediatrics.2018.2530

96. Zhang, T. , Wang, S., Wan, N., Zhang, L., Zhang, Z., \& Jiang, J. (2018). Cost-effectiveness of Daratumumab-based Triplet Therapies in Patients With Relapsed or Refractory Multiple Myeloma. Clinical therapeutics, 40(7), 11221139. https://doi.org/10.1016/j.clinthera.2018.05.012

97. Zheng, H., Qin, Z., Qiu, X., Zhan, M., Wen, F., \& Xu, T. (2020). Cost-effectiveness analysis of ramucirumab treatment for patients with hepatocellular carcinoma who progressed on sorafenib with $\alpha$-fetoprotein concentrations of at least $400 \mathrm{ng} / \mathrm{ml}$. Journal of medical economics, 23(4), 347-352. https://doi.org/10.1080/13696998.2019.1707211

98. Zori, R., Ahring, K., Burton, B., Pastores, G. M., Rutsch, F., Jha, A., Jurecki, E., Rowell, R., \& Harding, C. (2019). Long-term comparative effectiveness of pegvaliase versus standard of care comparators in adults with phenylketonuria. Molecular genetics and metabolism, 128(1-2), 92-101. https://doi.org/10.1016/j.ymgme.2019.07.018 